\title{
LAS FAMILIAS ENSAMBLADAS Y SU TUTELA CONSTITUCIONAL NUEVAS CONSIDERACIONES A PROPÓSITO DEL CASO MEDINA MENÉNDEZ
}

\author{
BLENDED FAMILIES AND THEIR CONSTITUTIONAL PROTECTION \\ NEW CONSIDERATIONS REGARDING THE MEDINA MENENDEZ CASE
}

\author{
Mosi Marcela Meza Figueroa* \\ Jakelín Verónica Nicolás de la Cruz \\ Diana Mileny Uchuypuma Tupia*** \\ Yerina Rocío López Aburto ${ }^{* * * *}$
}

\section{Resumen}

El cumplimiento del deber constitucional que tiene el Estado de proteger a la familia requiere de la comprensión de su naturaleza dinámica. Es propósito del presente artículo analizar las implicancias jurídicas de las nuevas estructuras familiares, en particular, de aquellas denominadas familias ensambladas, a partir de su reconocimiento en la jurisprudencia constitucional, con el objeto de lograr su óptima tutela.

Palabras clave: Derecho Constitucional, familia, familia tradicional, nuevas estructuras familiares, familia ensamblada.

\section{Abstract}

The fulfillment of the constitutional duty of the State to protect the family requires an understanding of its dynamic nature. The purpose of this article is to analyze the legal implications of the new family structures, in particular those known as blended families, from their recognition in constitutional jurisprudence, in order to achieve their optimal protection.

Keywords: Constitutional Law, family, traditional family, new family structures, blended family.

Magíster en Derecho Constitucional por la Pontificia Universidad Católica del Perú. Abogada por la Universidad Nacional Federico Villarreal. Profesora de Derecho Constitucional en la Universidad Femenina del Sagrado Corazón - UNIFÉ y en la Universidad Nacional Mayor de San Marcos. Asesora jurisdiccional del Tribunal Constitucional. Docente fundadora y responsable del Círculo de Estudios de Derecho Constitucional y Derechos Humanos de UNIFÉ - CEDEC.

** Estudiante del VIII ciclo de la Facultad de Derecho de la UNIFÉ. Coordinadora del Área de Investigación de Cedec.

*** Bachiller en Derecho por la UNIFÉ. Miembro del Área de Investigación de CEDEC.

****+ Estudiante del VIII ciclo de la Facultad de Derecho de la UNIFÉ. Miembro del Área de Investigación de CEDEC. 


\section{INTRODUCCIÓN}

Cuna de irradiación de valores y cultura, centro de formación del carácter, espacio de refugio personal frente a amenazas de la sociedad. Todo ello y más es la familia. No en vano es considerada como el núcleo indispensable para el crecimiento, desarrollo y supervivencia de las personas.

La familia es, con justicia, la célula básica de la sociedad, pues en su seno alberga a las generaciones que conforman el elemento vital de los Estados. Su importancia para el ser humano es tal que las naciones han visto la necesidad de reconocerla y protegerla en sus diversos ordenamientos jurídicos.

No obstante su trascendencia $-\mathrm{O}$, quizás, a propósito de ella-, subsisten legítimas controversias respecto de su origen, definición y composición. Estas diferencias, agudizadas en épocas recientes, están vinculadas a la aparición de nuevas estructuras familiares que hacen virar la atención y preocupación —orientada regularmente a aquellos modelos tradicionales- hacia las familias ensambladas.

El surgimiento de estas, denominadas también familias reconstituidas, obedece al dinamismo propio de nuestras sociedades y sus instituciones. El Estado - en cumplimiento de su deber constitucional de protección a la familia- no puede, pues, ser ajeno a esta realidad, por lo que le corresponde ejercer dicha obligación integralmente.

En el desempeño de su función jurisdiccional, a este respecto, se aprecia que los avances han sido valiosos, pues, a propósito de situaciones concretas de vulneraciones de derechos fundamentales hacia los integrantes de las familias ensambladas, y del estado de desprotección jurídica en la que se encontraban, el reconocimiento jurisprudencial realizado por el Tribunal Constitucional peruano implica una genuina preocupación por los conflictos que sobre estas puedan generarse.

Así es que, en el caso Shols Pérez, el supremo intérprete de la Constitución se pronunció por vez primera sobre las nuevas estructuras familiares, estableciendo algunas de sus características; en tanto que, recientemente, en el caso Medina Menéndez, desarrolla nuevas consideraciones sobre las familias ensambladas.

En el presente artículo, desarrollaremos el ámbito de protección constitucional de la familia, previa indagación sobre las diversas definiciones 
que esta ha merecido; repasaremos seguidamente los pronunciamientos del Tribunal Constitucional en los que ha acogido una tesis amplia y tuitiva de aquella, incorporando a las familias ensambladas ante el vacío legislativo nacional; $\mathrm{y}$, recurriremos finalmente al derecho comparado, así como a las sentencias y opiniones consultivas que los órganos supranacionales de protección de derechos humanos han emitido sobre esta institución fundamental de la sociedad, en el marco de sus nuevas estructuras.

\section{DEFINICIÓN DE FAMILIA}

"La familia no es un fenómeno inmóvil, sino en constante evolución o involución, aunque ello no sea perceptible día a día" (Cornejo, 1991). Esta realidad cambiante de la institución familiar dificulta su definición, generándose legítimas controversias relacionadas con sus alcances, límites y composición.

Bossert y Zannoni (2004) consideran que la familia: "es una institución permanente que está integrada por personas cuyos vínculos derivan de la unión intersexual, de la procreación y del parentesco" (p.5); por su parte, Varsi (2011) afirma que esta tiene una multiplicidad de definiciones: legal, política, sociológica, filosófica, antropológica, biológica; y, en todas ellas, la coincidencia es en el aspecto grupal, organizacional y la vinculación que existe entre sus integrantes (p.18)

Frente a estos disentimientos, resulta útil la etimología; empero, incluso en dicho terreno subsisten las diferencias. Así, nuevamente, Varsi (2011) señala que "el término familia procede del sánscrito, idioma de la lengua indoeuropea similar al latín y al griego en Europa, dhaque significa asentar y dhaman asiento, morada". (p.13); en tanto que Cornejo (1991) refiere que este "deriva de la palabra latina fames que significa hambre, haciendo referencia a la necesidad básica que se satisface en el seno de la familia". (p.21)

Ahora bien, con relación a su naturaleza, Eto (1989) precisa que la familia puede ser una:

a) Institución social: desde el punto de vista de la sociología, la familia constituiría una institución social en tanto que, las relaciones están determinadas por la unión intersexual, la procreación y el parentesco, los cuales constituyen un sistema integrado en la estructura social de la sociedad. En este criterio, la función única del derecho es imponer a los miembros de la familia deberes y derechos. 
b) Institución jurídica: Partiendo de la idea de que actualmente la familia ocupa un lugar en el derecho, es lógico que la familia sea considerada como una colectividad dotada de personalidad moral. Hay algunos autores que consideran que la familia es una persona jurídica y otros que es un organismo jurídico.

c) Institución jurídico-social: la familia trata de las relaciones familiares (tales como el matrimonio, reconocimiento de hijos) y a la vez es la célula social básica de la sociedad. (pp. 26-27)

El concepto que podamos tener de la familia, esto es, la representación mental asociada a un significante lingüístico ${ }^{110}$, probablemente esté siempre vinculado a la imagen de la familia tradicional; empero, las definiciones que se realicen sobre ella deberán ser tan vastas que integren no solo este modelo típico, sino también las nuevas estructuras familiares.

\section{PROTECCIÓN CONSTITUCIONAL DE LA FAMILIA}

Repasando nuestra historia constitucional, apreciamos que el instituto jurídico de la familia se encuentra reconocido a partir de la segunda norma fundamental del siglo XX.

En efecto, la Constitución de 1933 destinó dos artículos a su tratamiento, los cuales formaban parte del capítulo Garantías Nacionales y Sociales. Mientras que el artículo 51 establecía que "el matrimonio, la familia y la maternidad están bajo la protección de la ley", el artículo 52 orientaba su mirada a uno de sus integrantes: “... El Estado defiende el derecho del niño a la vida del hogar, a la educación, a la orientación vocacional, y a la amplia asistencia cuando se halle en situación de abandono, de enfermedad o de desgracia...."

A diferencia de aquella, la Constitución de 1979 dedicó un capítulo completo a la familia, definiéndola — de la mano con el matrimonio- como sociedad natural e institución fundamental de la Nación. Al considerar ambas figuras como un solo elemento que merece protección del Estado, es posible inferir que la carta precedente solo dirigía su atención a la familia matrimonial tradicional.

Considerar el origen natural de la familia implica, en términos de Cornejo Chávez, que esta trasciende al Estado y a la ley:

110 El Sétima acepción de la palabra concepto, proveniente de la Lingüística, según el Diccionario de la Lengua Española, de la Real Academia Española. 
Reconocer que la familia es una sociedad natural significa reconocer que la familia, como fenómeno natural, es anterior al Estado y a la ley; que no es una creación del Estado ni de la Ley, que antes de que hubiese ley y Estado, histórica, pero sobre todo conceptualmente, ya existía la familia.

Si eso es efectivamente lo que quiere decir el artículo, significa que la ley no puede hacer con la familia lo que quiera, sino que el carácter natural de ella le impone al propio Estado ciertos límites, de los cuales no puede salirse sin desnaturalizar a la familia. (Citado por Eto, 1989, p.38).

Para algunos autores, de otro lado, es un error concebir a la familia como un fenómeno natural, pues se trata, en realidad, de una construcción histórica. Así, en los inicios del hombre "primaron las relaciones sexuales con un carácter desordenado y la familia no existía aún" (Eto, 1989, p.38); incluso, antes de que apareciera la familia monogámica o tradicional existieron otros tipos de familia como la consanguínea, la punalúa y la sindiásmica, como se aprecia de la clasificación realizada por Engels (1884).

Por su parte, la Constitución Política vigente, si bien confiere a la familia una protección especial por parte de la comunidad y del Estado al igual que su antecesora, establece también algunas diferencias con relación al tratamiento del matrimonio: se protege a la familia y se promueve el matrimonio. Esta distinción resulta neurálgica, pues extiende el campo de interpretación del concepto de familia, reconociendo que el matrimonio no es la única vía para constituirla, sino que existen otros caminos para ello, como la convivencia o la unión de hecho (Fernández, 2013, p.27), que también se encuentra reconocida y protegida por el texto constitucional.

Sin embargo, a pesar de que nuestra norma suprema no sea restrictiva respecto al entendimiento del instituto de la familia - pues solo se refiere a ella mas no la define ni establece un tipo predeterminado-, aún se sigue considerando a este modelo tradicional como único, generando así desprotección a ciertos grupos familiares que no se ajustan al mismo.

Precisamente, en el caso Shols Pérez ${ }^{111}$, el Tribunal Constitucional tuvo oportunidad de pronunciarse con relación a este tipo de controversias:

Desde una perspectiva constitucional, debe indicarse que la familia, al ser un instituto natural, se encuentra inevitablemente a merced de los

111 Sentencia del Tribunal Constitucional recaída en el Expediente 09332-2006-PA/TC y publicada en el portal web institucional el 6 de febrero de 2008 
nuevos contextos sociales. Así, cambios sociales y jurídicos tales como la inclusión social y laboral de la mujer, la regulación del divorcio y su alto grado de incidencia, las grandes migraciones hacia las ciudades, entre otros aspectos, han significado un cambio en la estructura de la familia tradicional nuclear, conformada alrededor de la figura del pater familias. Consecuencia de ello es que se hayan generado familias con estructuras distintas a la tradicional, como son las surgidas de las uniones de hecho, las monoparentales o las que en doctrina se han denominado familias reconstituidas. (Fundamento 7).

La amplia perspectiva de la familia sostenida por el supremo intérprete de la constitución supone que los diferentes tipos o estructuras familiares surgidas de los contextos sociales actuales gozan de igual protección.

\section{CONSIDERACIONES DEL TRIBUNAL CONSTITUCIONAL SOBRE LAS FAMILIAS ENSAMBLADAS}

Como ya se había mencionado, la protección constitucional de la familia se extiende también a las nuevas estructuras familiares; sin embargo, en la práctica se sigue dando un trato diferenciado a los integrantes de familias de composición distinta a la de las familias tradicionales.

Así también lo reconoce el Tribunal Constitucional en el aludido caso Shols Pérez, cuando expresa que por lo general en el caso de familias ensambladas los hijos afines son tratados de manera distinta a los hijos biológicos pues se cuestiona el vínculo existente entre los padres afines (padrastros o madrastras) y sus hijos afines (hijastros/as) y los derechos y deberes que estos adquieren al constituirse en una nueva familia, puesto que tales derechos y deberes no están contemplados en nuestro ordenamiento jurídico de manera explícita.

En efecto, el señor Reynaldo Armando Shols Pérez inició un proceso de amparo contra el Centro Naval del Perú por vulnerar su derecho a la igualdad, toda vez que este se negó a otorgar el carné familiar a su hija afín, alegando la no existencia de una relación de consanguinidad entre ambos.

En este caso, el supremo intérprete de la Constitución establece los lineamientos jurídicos sobre la familia ensamblada; así, citando a Beatriz Ramos Cabanellas, la definió como aquella "estructura familiar originada en el matrimonio o la unión concubinaria de una pareja en la cual uno o ambos de sus integrantes tienen hijos provenientes de una relación previa" (Fundamento 8). 
Esta nueva familia que se constituye establece una nueva identidad familiar que genera a su vez derechos y deberes que no pueden ser obviados por la sociedad y el Estado, pues, de lo contrario, se estaría contraviniendo nuestra norma suprema, la cual, además de brindar protección a la familia, en el tercer párrafo de su artículo 6 expresa que todos los hijos tienen iguales derechos y deberes, proscribiendo toda mención al estado civil de los padres o a la naturaleza de la filiación. En tal sentido, no puede darse un trato diferenciado a los hijos afines que forman parte de una familia ensamblada con respecto de los hijos biológicos, toda vez que resulta lesivo para los menores y para la nueva identidad familiar.

Asimismo, existen ciertas características que el Tribunal Constitucional ha considerado en el precitado caso, que son propias de una familia ensamblada:

a. Es una estructura familiar que puede originarse de la unión matrimonial o de la unión concubinaria (fundamento 8).

b. Está integrada por una pareja en la cual uno de ellos o ambos tienen hijos de una relación anterior (fundamento 8).

c. Los miembros de la familia ensamblada deben de "habitar y compartir vida de familia con cierta estabilidad, publicidad y reconocimiento". (Fundamento 12). Es decir, que esta nueva familia constituida debe tener una identidad propia y autónoma en donde los padres e hijos, sean biológicos o afines, tienen sus roles claramente establecidos y conviven públicamente.

Recientemente, el alto colegiado se volvió a pronunciar sobre la familia ensamblada y estableció nuevas consideraciones en torno a ella. En el caso Medina Menéndez ${ }^{112}$-referido al cuestionamiento de un despido fraudulento basado, entre otras razones, en la afiliación como derechohabiente de la hija biológica del cónyuge del demandante a Pacífico EPS-enumeró sus principales características, enfatizando que estas son esencialmente descriptivas, por lo que no se trata de un numerus clausus (fundamento 34):

(i) Comprende una pareja cuyos integrantes deciden voluntariamente fusionar sus proyectos de vida, y en la cual uno de ellos o ambos posee hijos de una relación previa. También comprende a parientes con lazos cercanos que voluntariamente deciden hacerse cargo de la atención, cuidado y desarrollo del niño o niña en forma habitual.

112 Sentencia del Tribunal Constitucional recaída en el Expediente 01204-2017-PA/TC y publicada en el portal web institucional el 4 de marzo del 2019. En ella, el Tribunal declaró fundada la demanda de amparo, puesto que reconoció que entre los padres e hijos afines hay un deber de asistencia inmediata y recíproca, por lo que el actor no ha incurrido en ninguna causal que amerite su despido. 
(ii) Generalmente, se originan por razones de abandono, viudez, divorcio o separación de uniones de hecho. Este último, en base a la relación de equivalencia que existe en nuestro ordenamiento entre el matrimonio y la unión de hecho; tal como lo ha dispuesto el artículo 5 de la Constitución y el artículo 326 del Código Civil (Cfr. STC 09708-2006-AA/TC).

(iii) La nueva identidad familiar debe guardar algunas características para reconocerse como tal. Estas características pueden consistir en "habitar y compartir vida de familia con cierta estabilidad, publicidad y reconocimiento" (STC 09332-2006-PA/TC).

Una de las novedades de esta sentencia es aquella referida al reconocimiento de los parientes cercanos, distintos de los padres, que se hacen cargo de los niños de modo habitual, como parte de las familias ensambladas. Así, en caso de abandono u orfandad del menor, los abuelos, tíos $\mathrm{u}$ otros parientes que decidan voluntariamente hacerse cargo de él constituirán también una de estas familias. Empero, no se delimita en dicho pronunciamiento constitucional cuáles son las obligaciones y derechos que tienen como parte de esta nueva estructura familiar.

Incluso, con relación a los derechos y deberes que tienen los padres afines, también denominados progenitores sociales o padres no biológicos, y los hijos afines dentro de la familia ensamblada, en el caso De la Cruz Flores ${ }^{113}$, el Tribunal Constitucional reconoce que nuestro ordenamiento jurídico no los contempla expresamente, razón por la cual aún no se ha determinado, por ejemplo, las obligaciones alimentarias que entre estos se generan. Señala además que, si bien en el caso Shols Pérez se determinó que la diferenciación realizada por la demandada entre la hija biológica y la hija afín del actor no era razonable, configurándose por tanto un acto arbitrario, no se precisó que ambas gocen de los mismos derechos y obligaciones.

Sin embargo, en el caso Medina Menéndez, el supremo intérprete de la Constitución sí se pronuncia al respecto:

[...] resulta pertinente señalar que existen obligaciones que tiene el padre o madre afín, derivadas del reconocimiento de una familia ensamblada, Y es que resulta claro que si se identifica la existencia de este tipo de familia,

113 Sentencia del Tribunal Constitucional recaída en el Expediente 04493-2008-PA/TC y publicada en el portal web institucional el 26 de octubre de 2010. Este caso corresponde a un proceso de amparo contra una resolución judicial que ordenó la reducción del monto de alimentos que había sido establecido en favor de la hija biológica de la demandante, en atención al deber familiar que tenía el padre biológico de la menor con sus tres hijos afines. El colegiado declaró fundada la demanda y nula la resolución judicial aludida por falta de motivación, al conceder la reducción de alimentos pese a que el padre de la menor no acreditó válidamente tener un vínculo matrimonial o una situación de unión de hecho. 
el padre o madre afín tiene el deber de brindar mínimamente una asistencia inmediata $\mathrm{y}$, principalmente, dirigida a la sobrevivencia en condiciones dignas del menor, esto es, a la atención, cuidado y desarrollo del mismo. Esta situación conllevará, como consecuencia lógica, a que dicha obligación se extienda también del hijo o hija hacia el padre o madre afín cuando estos últimos necesiten asistencia como, por ejemplo, cuando estos lleguen a la vejez o sufran una discapacidad permanente. (Fundamento 36)

Así bien, el padre o la madre afín tiene el deber de brindar a sus hijos afines mínimamente una asistencia inmediata de manera que las necesidades primarias del menor se vean cubiertas, sin que ello signifique que el padre o la madre biológica se haya liberado de las responsabilidades legales que tiene con sus hijos, o que haya perdido la patria potestad de los mismos. Asimismo, resulta importante destacar que el Tribunal Constitucional, atendiendo al principio de reciprocidad, establece que los hijos afines tienen también el deber de asistir a su madre o padre afín cuando estos se encuentren en estado de necesidad.

Tales consideraciones, añade el Tribunal, se deben principalmente a "razones vinculadas a la solidaridad, a la afectividad respecto a la nueva unidad familiar y a una posible situación de irreparabilidad en la que podría caer el menor si carece de la asistencia a la que el padre biológico está obligado pero que, muchas veces, incumple". (Fundamento 37). Es decir, antes que una obligación legal, el deber de asistir de los padres afines a sus hijos no biológicos es una obligación moral que nace de la afectividad y la solidaridad hacia la nueva familia que han constituido.

\section{TRATAMIENTO JURÍDICO INTERNO Y LEGISLACIÓN COMPARADA}

Como se ha venido señalando, en las últimas décadas las familias han sufrido cambios importantes debido a los nuevos escenarios de nuestra sociedad, lo que ha dado origen a tipos de familias con estructuras distintas a la tradicional. En Latinoamérica y Europa crece el número de familias ensambladas, y la respuesta a esta realidad es distinta en cada Estado. Por ello, a continuación, realizaremos un análisis de nuestra legislación interna y la legislación de algunos países de la región y del Viejo Continente: Argentina, Colombia, Ecuador, España y Holanda.

Sabido es que nuestro Código Civil de 1984, debido al contexto social en el que fue promulgado, contiene disposiciones que regulan a la familia formada a partir del matrimonio. Sin embargo, algunas de ellas pueden 
ser interpretadas de manera tal que permitan incorporar a las familias ensambladas en su ámbito de aplicación, empero, estas no resultan ser suficientes. Si bien es cierto que el Tribunal Constitucional en los casos Shols Pérez y Medina Menéndez se ha pronunciado sobre la estructura de la familia ensamblada y los deberes de sus integrantes, respectivamente, subsiste un vacío respecto de los alcances de estos deberes.

No hay duda que, desde un punto de vista emocional, se crean vínculos entre el padre o madre afín y los hijos afines, que puede ser de amor o de odio, pero, independientemente de ello, también se crea un vínculo jurídico que a su vez va a generar derechos y deberes entre los integrantes de dicha familia.

El Tribunal Constitucional en el caso Shols Pérez expresó que del artículo 237 del Código Civil se desprende que entre los padres afines y sus hijos no biológicos existe un parentesco de afinidad:

Las relaciones entre padrastros o madrastras y los hijastros/as deben ser observadas de acuerdo con los matices que el propio contexto impone. Por ejemplo, del artículo 237. ${ }^{\circ}$ del Código Civil (CC), se infiere que entre ellos se genera un parentesco por afinidad, lo que, de por sí, conlleva un efecto tan relevante como es el impedimento matrimonial (artículo $242^{\circ}$ del CC). (Fundamento 10)

El referido artículo, en su primer párrafo, expresa que "el matrimonio produce parentesco de afinidad entre cada uno de los cónyuges con los parientes consanguíneos del otro". Sin embargo, existen también otras disposiciones del mismo código que, por ser más restrictivas, no pueden ser aplicadas automáticamente a las familias ensambladas; así el artículo 474 establece que se deben alimentos recíprocamente los cónyuges, los ascendientes y descendientes, y los hermanos, omitiendo pronunciarse respecto a los padres e hijos afines (Esquivel, 2017, p.61).

Al respecto, mencionamos precedentemente que la última sentencia del Tribunal Constitucional sobre familias ensambladas (caso Medina Menéndez) reconoce la existencia de un deber de asistencia familiar inmediato entre los padres e hijos afines y que este es recíproco. En tal sentido, de la presente jurisprudencia constitucional podría argumentarse que, a pesar de que el artículo 474 del Código Civil no contempla tal supuesto, también se deben alimentos recíprocamente los padres e hijos afines, en determinados supuestos. 
Desde que la familia ensamblada fue reconocida por el Tribunal Constitucional en el caso Shols Pérez, había surgido la interrogante sobre cuáles eran los derechos y deberes aplicables a esta nueva estructura familiar puesto que el Código Civil no la regula. Si bien es cierto que aún existe un vacío legal al respecto y que el Perú es uno de los países latinoamericanos que no ha sabido responder rápidamente a estos cambios sociales, las entidades encargadas de administrar justicia, atendiendo a su deber de no dejar de hacerlo a pesar de las lagunas legales, están estableciendo criterios que regulan a la familia ensamblada, los cuales esperamos sean desarrollados con mayor detalle en una norma positivizada prontamente.

Es importante mencionar que un referente de la región a este respecto es Argentina, país que reconoce de manera explícita a las familias ensambladas. Así, en el Capítulo 7 del Título VII Responsabilidad Parental del Libro Segundo Relaciones de Familia de su Código Civil y Comercial ha incorporado los "Deberes y derechos de los progenitores e hijos afines" (Ministerio de Justicia y Derechos Humanos, 2016).

Este capítulo está compuesto por cinco artículos (del 672 al 676), referidos al progenitor afín, sus deberes, la delegación en el progenitor afín, el ejercicio conjunto con el progenitor afín y los alimentos. El primero define quien es el progenitor afín; el segundo menciona las obligaciones que tiene con el hijo afín, como la de cooperar en su crianza y educación, adoptar decisiones ante situaciones de emergencia, entre otras, las cuales no afectan las responsabilidades que competen a los padres biológicos; el tercero establece que, en caso el progenitor no pueda ejercer su responsabilidad parental, podrá delegarlo a su cónyuge o conviviente, siempre que exista imposibilidad para su desempeño por parte del otro progenitor; la cuarta plantea que en caso el progenitor fallezca, esté ausente o sea declarado incapaz, el otro progenitor podrá conjuntamente asumir las obligaciones derivadas de la filiación con su cónyuge o conviviente; y, el quinto señala que la obligación alimentaria del padre afín es de índole subsidiaria y cesa en los casos de disolución del vínculo conyugal o ruptura de la convivencia.

En un interesante estudio realizado por una autora argentina sobre las familias ensambladas en dicho país hacia el año 2001, se aprecia que "cerca de 1 de cada 10 familias está compuesta por una pareja en unión reincidente", proporción que dieciocho años después ha debido verse notablemente incrementada. Al comentar acerca de estas nuevas estructuras familiares, Street (2001) refiere: 
La recomposición familiar a causa de la reincidencia en una nueva unión no es un fenómeno reciente. Sin embargo, lo que resulta novedoso en la actualidad es que, a diferencia del pasado, no se produce a causa del fallecimiento de uno de los cónyuges sino principalmente como consecuencia de la ruptura conyugal por separación o divorcio, lo que significa que cuando se han tenido hijos de la unión anterior no es posible ignorar al padre ausente. De esta manera, la familia reconstituida o ensamblada constituye una estructura en la que confluyen varios subsistemas familiares, en la medida que comprende los vínculos entre padres e hijos (aquel que detenta la guarda y el que no convive), la nueva pareja de cada uno de ellos, los hijos tenidos en la nueva unión, las respectivas familias de origen, etc. (p.2)

Por su parte, en la legislación colombiana, el Código Civil hace una breve referencia a la familia ensamblada -sin utilizar dicho nomen iuris- en su Título VIII De las segundas nupcias; empero, este solo desarrolla aspectos patrimoniales de los hijos que provienen de la relación anterior, tales como la obligación de realizar un inventario de sus bienes y la necesidad de nombrar un curador, sea que los menores tengan bienes o no. (Fernández, 2016, pp. 100-101)

Ecuador, a nivel constitucional, reconoce de forma genérica los distintos tipos de familia en su artículo 67; sin embargo, el tratamiento que realiza respecto de las familias ensambladas en su Código Civil es similar al de Colombia. Así, en el Título IV denominado De las segundas y ulteriores nupcias, desarrolla también aspectos patrimoniales: la obligación del padre que quisiere volver a casarse de realizar el inventario de los hijos, el nombramiento de un curador especial y la pérdida del derecho sucesorio en caso los padres no cumplan con realizar el referido inventario.

Trasladándonos a un territorio más lejano, apreciamos que España no contempla de manera expresa a las familias ensambladas en su normativa interna, pero debe reconocerse su contemplación implícita en los artículos 68, 155.2 y 1362 del Código Civil, entre los que cabe destacar el referido al deber alimentario y educativo de la sociedad de gananciales respecto de los hijos afines (utilizando otros términos, claro está). En esa línea, refieren Vaquer e Ibarz (2017) lo siguiente:

El Código civil no contempla unitariamente las familias reconstituidas, pese a que el derecho de familia es el área que más reformas ha experimentado en los últimos años. Apenas el art. 1362, 1ํ.2C C considera como carga de la sociedad de gananciales los gastos de alimentación 
y educación de los hijos de uno solo de los cónyuges que convivan en el hogar familiar; en contrapartida, el art. $155.2^{\circ}$ CC establece que los hijos -sin distingos entre comunes y no comunes- debe (sic) contribuir equitativamente al levantamiento de cargas familiares. También puede señalarse que el art. 68 CC prevé como deber conyugal el cuidado y atención de descendientes, sin especificar que sean comunes, si bien es evidente que no se contempla expresamente la familia reconstituida. (p.214)

Finalmente, en el Código Civil holandés se establece la obligación de manutención del padre afín. Así, el artículo 395 establece este deber en tanto dure el matrimonio o la convivencia y en la medida que el menor sea un miembro de la familia ${ }^{114}$. Empero, como anotan Cruz y Novoa (2018), la generalidad de esta disposición puede no ser suficiente para dar solución a una serie de controversias generadas al interior de familias ensambladas, como la imposibilidad del padre afín de mantener al hijo afín, en la medida que sus ingresos solo le permiten cubrir las necesidades de sus hijos biológicos. (p.35)

\section{TRATAMIENTO JURISPRUDENCIAL SUPRANACIONAL}

A nivel supranacional, se aprecia que tanto la Corte Interamericana de Derechos Humanos como el Tribunal Europeo de Derechos Humanos se han pronunciado en múltiples sentencias respecto de la nueva concepción de la institución de la familia, apartándose de una definición meramente tradicional.

Así, la Corte Interamericana, en el caso Atala Riffo y niñas vs Chile ${ }^{115}$, señaló que la Convención Americana de Derechos Humanos no tiene un concepto cerrado de familia; por ello, la vida familiar no se reduce únicamente al matrimonio, debiendo abarcar otros lazos familiares de hecho.

A mayor abundamiento, en el caso Ramírez Escobar y otros vs Guatemala ${ }^{116}$, dicha Corte reitera la concepción amplia de la familia, incorporando incluso como titulares del derecho a la vida familiar otros parientes, como los tíos, primos y abuelos, siempre que estos tengan lazos cercanos personales.

\footnotetext{
114 Traducción propia de la versión en inglés del Código Civil holandés, contenida en: http://www.dutchcivillaw. com/civilcodebook01.htm

115 Fundamento 142 de la sentencia de 24 de febrero de 2012.

116 Fundamento 163 de la sentencia de 9 de marzo de 2018.
} 
El Tribunal Europeo, por su parte, también se ha pronunciado al respecto en los casos K.A.B. c. España ${ }^{117}$; y, Kroon y otros c. Países Bajos ${ }^{118}$, y ha puntualizado que la noción de familia no está limitada por las relaciones fundadas en el matrimonio, por lo que puede englobar otros lazos familiares.

\section{OPINIONES CONSULTIVAS SUPRANACIONALES SOBRE LA FAMILIA}

La Convención Americana sobre Derechos Humanos en su artículo 17.1 ha establecido un precepto general sobre la familia, describiéndola como "el elemento natural y fundamental de la sociedad" que "debe ser protegida por la sociedad y el Estado".

El surgimiento de nuevas estructuras familiares ha motivado que los Estados y sus ciudadanos recurran a instancias supranacionales con el objeto de encontrar respuestas sobre las actuales concepciones de familia y la protección jurídica que estas puedan tener, en el marco de la precitada disposición convencional.

De esta manera, la Corte Interamericana de Derechos Humanos se ha pronunciado al respecto a través de reiteradas opiniones consultivas, enfatizando que la familia no es una institución estática, sino que responde a los cambios y nuevos contextos sociales y culturales, por lo que los ordenamientos jurídicos internos de los Estados debieran de adaptarse a ella.

En la Opinión Consultiva OC-24/17119 la Corte señaló que "en la Convención Americana no se encuentra determinado un concepto cerrado de familia, ni mucho menos se protege solo un modelo en particular de la misma". (párr. 174). Al respecto, conforme ya se ha detallado lo mismo sucede con nuestro ordenamiento jurídico interno que no ha establecido una definición única sobre la familia ni extiende su protección a un solo modelo predeterminado.

La realidad nos demuestra que los hogares no solo están conformados por padres e hijos, sino que también encontramos a otros parientes cercanos que forman parte de la dinámica familiar; y así lo reconoce también la Corte en la Opinión Consultiva OC-21/14 ${ }^{120}$ al considerar que:

\footnotetext{
Sentencia de 10 de abril de 2012.

Sentencia de 27 de octubre de 1994.

19 Opinión consultiva emitida el 24 de noviembre del 2017, solicitada por la República de Costa Rica sobre la identidad de género, e igualdad y no discriminación a parejas del mismo sexo.

120 Opinión consultiva emitida el 19 de agosto del 2014, solicitada por la República de Argentina, la República Federativa de Brasil, la República del Paraguay y la República Oriental del Uruguay sobre los derechos y garantías de niñas y niños en el contexto de la migración y/o en necesidad de protección internacional.
} 
La definición de familia no debe restringirse por la noción tradicional de una pareja y sus hijos, pues también pueden ser titulares del derecho a la vida familiar otros parientes, como los tíos, primos y abuelos, para enumerar sólo algunos miembros posibles de la familia extensa, siempre que tengan lazos cercanos personales. Además, en muchas familias la(s) persona(s) a cargo de la atención, el cuidado y el desarrollo de una niña o niño en forma legal o habitual no son los padres biológicos. (párr. 272).

Estas opiniones favorables al reconocimiento de las diferentes estructuras familiares que hoy coexisten en nuestras sociedades, emitidas por el órgano regional de tutela de los derechos humanos, deben ser, pues, analizadas por cada Estado de la mano con su propio ordenamiento constitucional, a fin de adoptar las medidas correspondientes que coadyuven a su protección.

\section{CONCLUSIONES}

1. La familia es conceptualizada regularmente en su manifestación tradicional; empero, al ser una institución jurídico-social cambiante, su definición debe adaptarse a la realidad e incorporar las nuevas estructuras familiares, como aquellas denominadas familias ensambladas, entendidas por el Tribunal Constitucional como aquellas originadas en el matrimonio o la unión concubinaria de una pareja en la cual uno o ambos de sus integrantes tienen hijos provenientes de una relación previa.

2. La institución familiar ha sido reconocida constitucionalmente a partir de la norma suprema de 1933; empero, es la Constitución de 1979 la que le dedica un capítulo completo y la reconoce, junto al matrimonio, como una sociedad natural e institución fundamental de la nación, asociación terminológica que manifiesta el carácter tradicional asignado.

3. La Constitución de 1993 mantiene los preceptos generales de su predecesora, pero realiza una importante precisión respecto del rol de la comunidad y el Estado sobre la familia y el matrimonio: protegen el primero y promueven el segundo. Esta disposición contenida en el artículo 4, aunada a aquella comprendida en el artículo siguiente, sobre el concubinato, permiten realizar una interpretación amplia de la familia que incorpore a las nuevas estructuras familiares. 
4. El Tribunal Constitucional peruano ha tenido ocasión de desarrollar una nueva definición de familia, en la que acoge a las familias ensambladas. Así, en el caso Shols Pérez, publicadoel 2008, estableció algunas características propias de esta nueva estructura familiar: i) origen: unión matrimonial o concubinaria; ii) conformación: una pareja en la cual uno o ambos tienen hijos de una relación anterior; $y$, iii) convivencia: deber de habitar y compartir vida de familia con cierta estabilidad, publicidad y reconocimiento, de manera tal que se establezca una identidad familiar propia y autónoma.

5. En el caso Medina Menéndez, publicado el 2019, el supremo colegiado estableció nuevas consideraciones en torno a la familia ensamblada: i) integrantes: además de estar conformada por una pareja y sus hijos biológicos y afines, también comprende a parientes con lazos cercanos que voluntariamente deciden hacerse cargo del menor en forma habitual; ii) origen: razones de abandono, viudez, divorcio o separación de uniones de hecho; iii) identidad familiar: en este extremo reitera lo señalado en el caso Shols Pérez; y, iv) obligaciones: asistencia inmediata de padres a hijos afines, dirigida a su atención, cuidado y desarrollo, y, recíprocamente, asistencia de estos a su padre o madre afín en situaciones de vejez o discapacidad permanente. Estos deberes mutuos se encuentran basados en la afectividad y la solidaridad, sin que ello suponga que los padres biológicos dejen de cumplir sus responsabilidades legales o pierdan la patria potestad de sus hijos.

6. Si bien la jurisprudencia constitucional ha reconocido expresamente a las familias ensambladas, desarrollando sus principales cualidades, ello es insuficiente, pues, nuestra legislación civil no ha regulado estas nuevas estructuras familiares, subsistiendo así vacíos normativos respecto de los derechos y deberes específicos de sus integrantes, pues aquellos reconocidos y asignados a las familias matrimoniales no pueden ser de aplicación automática e integral.

7. En el derecho comparado analizado (Argentina, Colombia, Ecuador, España y Holanda) se aprecia un reconocimiento de las familias ensambladas, sea este explícito o implícito. De ellos, cabe resaltar el Código Civil y Comercial de Argentina, que desarrolla de manera más completa ciertos temas referidos a este tipo de familia, referidos básicamente a las obligaciones de los padres afines y, en particular, su deber alimentario subsidiario frente a los hijos afines. 
8. En el ámbito supranacional, tanto interamericano como europeo - a través de sus sentencias $\mathrm{y} / \mathrm{u}$ opiniones consultivas-, se hace patente la comprensión de la familia como una institución dinámica, que se ve alterada por los cambios sociales, razón por la cual su noción no se limita al modelo tradicional, incorporando incluso, en el caso Ramírez Escobar y otros vs Guatemala, a los tíos, primos y abuelos, siempre que tengan lazos cercanos personales.

9. El mandato constitucional de protección a la familia - y de manera especial al niño, al adolescente, a la madre y al anciano en situación de abandono- exige un reconocimiento expreso de las nuevas estructuras familiares como la familia ensamblada. Si bien el Tribunal Constitucional ha emitido significativos pronunciamientos al respecto, aunados a los criterios interpretativos que puedan brindar las sentencias y opiniones consultivas de los órganos supranacionales, así como las lecciones que demuestra el derecho comparado, ello es aún insuficiente. Es necesaria una regulación detallada en nuestra legislación civil que desarrolle los distintos aspectos vinculados a aquella, sobre todo referidos a los derechos y deberes de los padres e hijos afines, de manera que no se generen situaciones de desprotección y, peor aún, irreparabilidad.

\section{REFERENCIAS}

Bossert, G. \& Zannoni, E. (2004). Manual de Derecho de Familia. 6ta edición. Astrea.

Corte Interamericana de Chile. Caso Atala Riffo y niñas vs Chile. Recuperado de http:/ / corteidh.or.cr/docs/casos/articulos/seriec_239_esp.pdf

Corte Interamericana de Chile. Caso Ramírez Escobar y otros vs Guatemala. Recuperado de: http://www.corteidh.or.cr/docs/casos/articulos/ seriec_351_esp.pdf

Corte Interamericana de Derechos Humanos: Opinión Consultiva OC-21/14. Recuperado de: https: / / www.acnur.org/5b6ca2644.pdf

Corte Interamericana de Derechos Humanos: Opinión Consultiva OC21/17. Recuperado de: http:/ /www.corteidh.or.cr/docs/opiniones/ seriea_24_esp.pdf

Cruz, F \& Novoa, A. (2018). Las familias ensambladas y su reconocimiento 
específico en el Código Civil peruano. Trujillo: Derecho Civil - Familia. p.35. Recuperado de http://repositorio.ucv.edu.pe/bitstream/ handle/UCV /28689/cruz_gf.pdf?sequence=1\&isAllowed=y

Cornejo, H. (1991). Derecho Familiar Peruano. Tomo I. Sociedad Conyugal. 8va Edición. Lima.

Engels, F. (1884). El origen de la familia, la propiedad privada y el Estado. Editorial Progreso.

Eto, G. (1989). Derecho de Familia en la Constitución y el nuevo Código Civil. Marsol Perú: Editores S.A.

Esquivel, J. (2017). La necesidad de un marco legal sobre los hijos afines menores de edad dentro de una familia ensamblada en el Perú. (Tesis de Pregrado). Universidad Privada Antenor Orrego. Trujillo, p. 61. Recuperado de: http: / / repositorio.upao.edu.pe/bitstream/upaorep/2876/1/RE_ DERE_JOSE.ESQUIBEL_NECESIDAD.DE.UN.MARCO.LEGAL_ DATOS.pdf

Fernández, R. (2013). Manual de Derecho de familia: Constitucionalización y diversidad familiar. Fondo Editorial PUCP.

Fernández,S. (2016). Regulación jurídica de la familia ensamblada en el Perú y en el derecho comparado (Tesis de Grado). Arequipa: Universidad Católica de Santa María. Recuperado de: https: / / alicia.concytec.gob.pe/vufind / Record/UCSM_df903d406ac3035d8b5bfe2a884875a5/Details

Gonzales, G. (2015). La necesidad de regular el deber de asistencia familiar mutua y los derechos sucesorios de la familia ensamblada en el Código Civil. (Tesis de Grado). Pimentel: Universidad Señor de Sipán. Recuperado de: http://repositorio.uss.edu.pe/bitstream/handle/ uss / 487 / GONZALEZ\%20REQUE\%20GUSTAVO\%20ADOLFO. pdf;jsessionid=F2F97B02870BA72D71A5A6E4B758E101? sequence=1

Ministerio de Justicia y Derechos Humanos (2014). Código Civil y Comercial de la Nación. Ministerio de Justicia y Derechos Humanos. Recuperado de http://www.saij.gob.ar/docs-f/codigo/Codigo_Civil_y_Comercial_ de_la_Nacion.pdf

Ministerio Público de la Defensa (s.f.). Boletín Electrónico de Jurisprudencia Internacional: Protección de la familia. Recuperado de: http://www. 
colectivoderechofamilia.com/wp-content/uploads/2015/04/ Bolet $\%$ C 3\% ADn-Electr\%C3\%B3nico-de-JurisprudenciaInternacional-emitido-por-el-Ministerio-P\%C3\%BAblico-de-laDefensa.pdf

Street, M. (2001). Las familias ensambladas en la Argentina hacia el año 2001. Descubriendo los "tuyos, los míos y los nuestros". Recuperado de: http:// www.redaepa.org.ar/sitio_anterior/viii/AEPA/B04/Street.pdf

Tribunal Constitucional (2007). Caso Shols Pérez, Sentencia EXP. № 09332-2006-PA/TC. Recuperado de: http://www.tc.gob.pe/ jurisprudencia/2008/09332-2006-AA.pdf

Tribunal Constitucional (2010). Caso De la Cruz Flores, Sentencia EXP. № 04493-2008-PA/TC. Recuperado de: http://blog.pucp.edu.pe/blog/ ariojabermudez/2010/12/01/exp-n-04493-2008-pa-tc-motivacionde-fallos/

Tribunal Constitucional (2018). Caso Medina Menéndez, Sentencia EXP № 01204-2017-PA/TC. Recuperado de: https://static.legis.pe/wpcontent/uploads/2019/04/Exp.-01204-2017-PA-TC-Lima-Legis.pe_. pdf

Vaquer, A. \& Ibarz, N. (2017). Las familias reconstituidas y la sucesión a título legal. Recuperado de: https://www.academia. edu/35555346/LAS_FAMILIAS_RECONSTITUIDAS_Y_LA_ SUCESI\%C3\%93N_A_T\%C3\%8DTULO_LEGAL

Varsi, E. (2011). Tratado de Derecho de Familia. Gaceta Jurídica.

Fecha de recepción: 15 de octubre de 2019

Fecha de aceptación: 04 de noviembre de 2019 
